Watermatex 2004: selected proceedings of the 6th IWA international symposium on systems analysis and integrated assessment (WATERMATEX 2004), 3-5th November 2004, Beijing, China. Chen, J. and Beck, M.B. (eds.)

Water science and technology, 53(1), pages 1-8.

DOI: $10.2166 /$ wst.2006.001

\title{
Integrated water resources management: lost on the road from ambition to realisation?
}

\section{P. Jeffrey and M. Gearey}

School of Water Sciences, Cranfield University, College Road, Cranfield, MK43 OAL UK

(E-mail: p.j.jeffrey@cranfield.ac.uk)

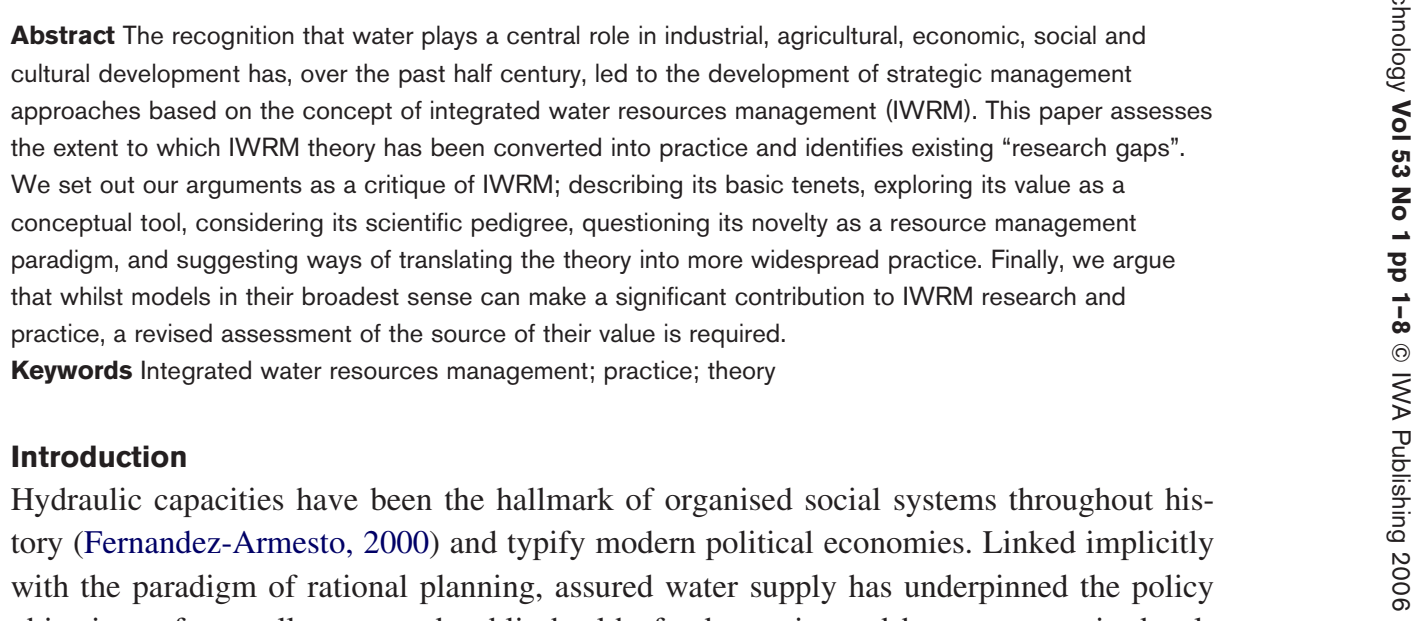
objectives of centrally managed public health, food security and hence economic development. This has placed the water sector, along with transport and energy, as one of the key infrastructural requirements of any modern society. Water supply is thereby locked chronologically with urbanisation, intensive agriculture, industrial economic development, central planning and the development of the modern nation state. The recognition that water plays a central role in industrial, agricultural, economic, social and cultural development has, over the past half century, led to the development of strategic management approaches based on the concept of integrated water resources management (IWRM).

IWRM has been advocated as the most sustainable means to incorporate the multiple competing and conflicting uses of water resources ever since the first UNESCO International Conference on Water, which took place in 1977 at Mar del Plata, Argentina. IWRM operates within a closely defined arena in developed economies, its trajectory mirroring the rise and fall of the "hydraulic mission" (Reisner, 1986). As IWRM became a necessity, as managing political economies became more complex, so the advent of postindustrial societies and growing water stress revealed a lacuna in the ability of IWRM's demand management approaches to tackle the phenomena of water stress.

Specifically, IWRM fails to address the problem of water stress as imminent. Whereas strains on supply are understood in terms of IWRM as meaning the diminution of supply headroom at times of peak demands or declining water quality, tackling water stress requires an intellectual shift to recognise that the agenda has moved from issues of supply reliability or demand reduction to more complex issues of variable water quality, excess and deficit water quantity; a shift which necessitates social, cultural and economic 
adaptation. As most developed societies will need to adjust to conditions of water stress this will necessitate a step on from supply augmentation and demand management towards harnessing adaptive capacity. Crudely, adaptive capacity details the way in which individuals, organisations and economic sectors will need to adjust to uncertain or ill-defined change. Adaptivity is the ability to cope with changing circumstances.

This evolution of water management paradigms from supply oriented, through demand oriented and on to multi-functional adaptive frameworks has been illustrated elsewhere (see Turton, 1999 for perhaps the most comprehensive statement) and arguments for strategies based on the promotion of adaptive capacity are well founded in the natural resources management literature (e.g. Gunderson and Holling, 2001). Adaptive management is currently promoted as an integrated, multidisciplinary approach for confronting uncertainty in natural resources issues (Walters, 1986). It acknowledges that the quality and availability of managed resources will always change as a result of human intervention, that surprises are inevitable, and that new uncertainties will emerge. Consequently it is characterised by policies which must be continually modified and flexible for adaptation to these surprises. In social (societal) terms, the key process of adaptivity is the ability to generate and exploit options for change.

The brief critique of IWRM presented below has one central purpose; to assess the extent to which IWRM theory has been converted into practice and identify existing "research gaps". It is comparable, though not necessarily complementary, with several recent contributions, in particular that which can be found in Kabat et al. (2002, pp. 60-62).

\section{What IWRM has been}

The Global Water Partnership (GWP) defines IWRM as "a process which promotes the co-ordinated development and management of water, land and related resources in order to maximise the resultant economic and social welfare in an equitable manner without compromising the sustainability of vital ecosystems" (GWP-TAC, 2000). Whilst there have been suggestions for modifications to this designation (e.g. Jonker, 2002, p. 719), the GWP version remains the most oft quoted version. As an ambition, IWRM therefore seeks to address (simultaneously!) two highly complicated and complex problem sets; sustainable development and cross-sectoral planning. Perhaps this expansive agenda has been the primary reason why the development of IWRM theory has been driven forward by a number of very astute and insightful commentaries (e.g. Hatcher, 1981; Biswas, 1981; Margerum and Born, 1995), and has recently been augmented by ideas from adaptive management (Holling, 1978) and complexity theory (Geldof, 1995). Latterly, "adaptive management" has been widely advocated as the paradigm which natural resource managers should adopt; building on a recognition that ecosystems are complex systems, which are "adaptive", or "self organising" and that management systems must be able to readjust to change or surprise in the system (Gunderson and Holling, 2001).

It is difficult to overstate the extent to which IWRM has become the norm or even, one might say, the orthodoxy in water resources management. Chapter 18 of the original Agenda 21 statement (United Nations, 1993) refers to the sustainable management of water resources being achieved through an integrated or holistic approach and IWRM is often referred to as the Dublin-Rio principle (ICWE, 1992) in that it highlights that fresh water is finite, vulnerable and that it is essential to sustain life, economic development and the environment. It also emphasises that water development and management should be based on a participatory approach, involving users, planners and policy makers at all levels. More recently, the World Water Council has proposed a "vision" for world water,

life and the environment which respects the principles of IWRM and embodies it in its 
concept for wider and practical applications (Abu-Zeid, 1998). Indeed, IWRM is now widely viewed as "the only sustainable solution" (Durham et al., 2002, p333) and therefore as the only game in town.

Many authors (e.g. Creighton, 1999) trace the beginnings of IWRM practice back to the creation of the Tennessee Valley Authority in the 1930s. This body worked across traditional sectoral borders and concerned itself with improving public health, flood control, power generation, water supply and regional economic stimulus. Other early examples of integration can be found in the Ruhr River Association in Germany and the River Basin Authorities created in the UK. However, detailed reviews of the history of IWRM can be found elsewhere (e.g. the excellent evaluation provided by White, 1998); our agenda here is analysis and scrutiny rather than description and explanation.

As IWRM strategies developed over the past 20 years the management of water resources solely to maximise consumptive use has given way to a realisation that management for environmental values, such as biodiversity, and social and cultural values is necessary (Cortner and Moote, 1994). Appropriate responses to water stress thereby become focused on augmenting water resources by improving the efficiency of supply, reducing leakage and recycling water, whilst trying to reduce demand through price changes, licensing structures, technology improvement and education campaigns in all user sectors. IWRM approaches have also emphasised the need for "joined up planning" across natural resource and economic development sectors. The need to adapt IWRM theory to local contexts makes generic description of strategies and techniques difficult. However, a set of IWRM principles which are (at least in part) characteristic of many national, regional and basin-scale strategies have been identified (IWA/UNEP, 2002):

- IWRM should be applied at catchment level.

- It is critical to integrate water and environmental management.

- A systems approach should be followed.

- Full participation by all stakeholders, including workers and the community.

- Attention to the social dimensions.

- Capacity building.

- Availability of information and the capacity to use it to anticipate developments.

- Full-cost pricing complemented by targeted subsidies.

- Central government support through the creation and maintenance of an enabling environment.

- Adoption of the best existing technologies and practices.

- Reliable and sustained financing.

- Equitable allocation of water resources.

- The recognition of water as an economic good.

- Strengthening the role of women in water management.

\section{IWRM failing to deliver}

So, if we were to adopt a critical posture for a moment and look for seditious commentary on IWRM, what might we find? The most common criticism is that the gap between theory and practice remains extensive. As a recent review article stated "There is still a long way to go to achieve a common understanding of IWRM and to develop and refine approaches for its successful implementation" (Jonker, 2002, p719). Perhaps the most insightful observation regarding this gap comes from a book review which, although published over a decade ago, still rings true today. The review draws attention to a shared "basic faith in the concept and aims of integrated management" but also points out that "despite some achievements and extraordinary capital investment, national governments have by and large failed to sustain truly integrative programmes" (Westcoat, 1992). 
Other commentaries have pointed out that IWRM is immature as a management tool. For example, "IWRM has neither been unambiguously defined, nor has the question of how it is to be implemented been fully addressed. What has to be integrated and how is it best done? Can the broad principles of IWRM be operationalised in practice - and, if so, how?" (GWP/TAC, 2000). Contemporary concern over this lack of success in application is such that the United Nations Environment Programme was recently prompted to classify the conversion of the concepts of integrated water resources management into practice as "unfinished business" (IWA/UNEP, 2002). Nevertheless, and irrespective of the specific criticisms levelled at the application of IWRM, we would suggest that the concept possesses two major weaknesses from which the bulk of its perceived failings arise: the nature of the science which has informed its development, and its curiously ambiguous character in terms of current intellectual paradigms.

\section{A science of IWRM?}

We would suggest that whilst the concept of IWRM has substantive intuitive influence, it remains a normative theory - a prescriptive framework derived largely from observation and focused on how things should be done. Despite its popularity (and one might say its reputation) IWRM remains: (i) a theory about, (ii) an argument for, and (iii) at best a set of principles for, a certain approach to water resources management. Empirical evidence which unambiguously demonstrates the benefits of IWRM is either missing or very poorly reported. Hence, there is no recipe book, no laws, no formulae, no blueprint. Little wonder then that the migration of IWRM from theory into practice has been sluggish.

This is not to say that a complete model of the operational details of IWRM (even in a generic form) is necessary for the development of practice. Rather a recognition of the type of scientific contribution being claimed (the nature of the evidence, the role of hypothesis, the validity and scope of conclusions etc.) is required. We argue not for a more quantitative model or verification of IWRM as process (as opposed to product and as emphasised by Born and Sonzogni, 1995), but for the recognition of the type of science being applied. Principally, we envisage a need for the development of new metrics (things to classify or measure), techniques (ways of classifying or measuring), and analytical frameworks (perspectives on the utility of classes or measures).

The position articulated above is not novel. For example, it was anticipated in the critical analysis put forward by Walther (1987) who suggested that idealistic beliefs in the problem-solving capacities of IWRM are not justified. Using three Canadian case studies, Walther's analysis concludes that the success and performance of IWRM, measured in terms of output such as formal decisions or plans, is primarily a function of the historical situation into which a project is placed, and only secondarily its professional design.

\section{Tensions between complexity and holism}

One avowed benefit of IWRM has been its adoption of a holistic approach that considers the contributions and perspectives of all users, planners, sciences and policy makers, thereby promoting increased communication between different public and private stakeholder groups as well as with the wider public. However, whilst IWRM reflects this post-modernist inspired agenda through its emphasis on contextual relevance, wider participation in planning and decision making, and responsive and reflexive practice, it remains rooted, by and large, in a "predict and prepare" paradigm. It is, therefore, more akin in practice to the contingency planning approaches of the 1960 s and 1970s than to the adaptive management frameworks promoted during the 1990s. Specifically, the IWRM movement has failed to take on board the implications 
of many of the ecological and evolutionary analogies which have prompted the calls for an "holistic" approach. This point is well demonstrated by the frequent assertion that the holistic agenda for IWRM is best supported where one government water agency is responsible for all water resource issues (e.g. Durham et al., 2002).

We would posit two central reasons for this retreat into modernism - a move which we are not in a position to make a value judgement about. Firstly, water management is, to be blunt, a serious business. Substantial changes to the way in which any resource is managed are risky (particularly where the transition costs and implications are largely unknown). A change from a single issue management strategy to IWRM implies significant and extensive transformations across several sectors. To undertake significant and extensive transformations which are the result of condensed accounts of a plurality of perceptions and interpretations of the problem does nothing to decrease the risk. Hence, and again to be somewhat blunt, to take on board the totality of the post-modernist agenda would be to risk public health and ultimately lives. Whilst the post-modernist agenda has much of value to offer, one suspects that its incorporation into practice will resemble a reformation rather than a revolution.

Secondly, it could well be that "ecosystems are not only more complex than we think, they are more complex than we can think", (Egler, quoted in Haney and Power, 1996. p879). A post-modern perspective raises the spectres of conditional and particular knowledge (i.e. knowledge as a function of experience and thereby neither absolute nor general). Such uncertainty (or, to be more precise, such "ambiguity"), is, as suggested above, an unwelcome guest where bad decisions can lead to such serious consequences. The post-modernist movement has also coincided with a greater recognition of the complexity of the natural world, and in particular of the relationships between society and nature. These concerns have found resonance in the emphasis within the IWRM research and practice community through the pursuance of new modes of political, institutional and human resource capacity to support IWRM strategies (see Radif, 1999, Schulze, 2001), and through explorations of "the knowledge gap between IWRM policy and practice" (Jewitt, 2002, p887). Such "implementation capacity" issues are attracting increasing attention from authors, many of whom echo White's observation that "The problems of accurate analysis of intersectoral linkages and of achieving institutional reforms in the planning process are formidable. It would be sanguine to expect early or easy solutions. Therefore, they deserve prompt, concerted attention." (White, 1998).

\section{Conclusions}

There are clearly a number of significant problems in realising the promise (we decline the use of the term "potential" as none has, to date, been clearly demonstrated) of IWRM. The assessment presented above has accepted that there is a problem but has attempted to go beyond description to attempt some degree of diagnosis. In summary, the verdict is that IWRM has proved problematic to migrate from theory (policy statement) to practice (policy tools/mechanisms) due to: (i) the nature of the science which has informed its development, and (ii) its schizophrenic character as part modernist and part post-modernist paradigm.

We would suggest that resolution of these two issues is a prerequisite for the unambiguous specification of IWRM as a concept and its effective implementation. We draw no conclusions as to whether such an objective is either practical or achievable. Nevertheless, without a clear exposition of how science can inform IWRM (i.e. its epistemological foundations), the research community is powerless to inform theory development, manage knowledge generation, or formulate prescriptive advice. 
A report prepared by the International Water Association in collaboration with the UNEP recently identified six obstacles to the implementation of IWRM as follows (IWA/UNEP, 2002):

- The lack of understanding of and attention to the positive contribution that innovative workplace approaches can play in achieving IWRM objectives.

- The potential complexity of the IWRM concept.

- The need for reference projects.

- The lack of adequate skills, expertise and awareness.

- The lack of adequate and reliable data.

- Gaps in available knowledge and technology.

The IWA embraces commercial, regulatory, practitioner and academic representation in its membership, a fact which strengthens the credibility and legitimacy of this particular document and its findings. Other groups have also made positive contributions to bridging the gap between IWRM theory and practices, often highlighting similar issues (inter alia Kabat et al., 2002). Although we have no wish to see these agendas subsumed or impaired by the analysis presented here, we would suggest five themes which might augment and enhance existing programmes of research:

1. The limits of science - what types of science can inform the IWRM field and how should the science-policy interface be managed.

2. The dynamics of diagnosis - relationships between what could and what can be done and exploration of the relationships between decision spaces and possibility spaces at individual, community and institutional scales.

3. The limits of intervention - identification of the extent to which the elements of a river basin system can be positively managed.

4. Learning by doing - identification of the rules for knowledge mapping between IWRM contexts and case studies.

5. Learning by training - curricula for cross-sectoral IWRM training and education.

Modelling (in the broadest sense of the word) can make a significant contribution to closing the knowledge gap between the theory and practice of IWRM. In general terms models allow us to represent the world around us in alternative formats; to abstract, simplify, conceptualise, and structure our beliefs about how the world works. In so doing they support analysis, experimentation, theory testing, communication, and planning. However, we would argue that the water sector will struggle to exploit this potential if its contemporary science and policy cultures continue to view the contribution of models primarily as product rather than process.

Because models are neither "sheer fictions" nor "adequate descriptions" (Caldin, 1949), but analogies, they reflect a set of interpretations, limitations, and assumptions which moulded their creation. Science has been bedevilled by misunderstandings as to the nature of models as analogies, and our choice of the term "modeling" rather than "models" at the opening of the previous paragraph is therefore more than symbolic. We would suggest that a significant fraction of the value of a modelling activity is a function of the experience of the modelling process rather than of the model itself. This is particularly true for models which span classes of phenomena, or cross disciplines, professions, or policy sectors. Useful responses to questions such as "what can I justifiably use this model for?", and "what are the limitations of this model?", are best sought in the history of a model's development. Collaborative or participatory modelling approach (as described in Garin et al., 2002) is one example of how the experience of the modelling activity can be valued. For such a reformation to become more widespread, both modellers and end-users will need to expand their views of what a model is and what it could do. 


\section{Acknowledgements}

The authors would like to acknowledge the financial support of the European Commission through the latter's support of the AQUADAPT (EVK1- CT-2001-00104) and NeWater (GOCE 511179) projects.

\section{References}

Abu-Zeid, M.A. (1998). Water and sustainable development: the vision for world water, life and the environment. Wat. Pol., 1, 9-19.

Biswas, A.K. (1981). Integrated water management: Some international dimensions. J. Hydrol., 51(1-4), 369-379.

Born, S.M. and Sonzogni, W.C. (1995). Integrated environmental management: strengthening the conceptualization. Env. Man., 19(2), 167-181.

Caldin, E.F. (1949). The Power and Limits of Science. Chapman and Hall, London, UK.

Cortner, H. and Moote, M. (1994). Trends and issues in land and water resources: Setting the agenda for change. Env. Man., 18, 167-173.

Creighton, S.C. (1999). Learning to plan for integrated water resources management in British Columbia. MA thesis, School of Community and Regional Planning, University of British Columbia, Canada.

Durham, B., Rinck-Pfeiffer, S. and Guendert, D. (2002). Integrated Water Resource Management through reuse and aquifer recharge. Desal., 152, 333-338.

Fernandez-Armesto, F. (2000). Civilizations. Macmillan, London, UK.

Garin, P., Rinaudo, J.-D. and Ruhlman, J. (2002). Linking expert evaluations with public consultation to design water policy at the watershed level. Wat. Sci. Tech., 46, 263-271.

Geldof, G.D. (1995). Adaptive water management: integrated water management on the edge of chaos. Wat. Sci. Tech., 32(1), 7-13.

Gunderson, L. and Holling, C.S. (2001). Panarchy: Understanding Transformations in Human and Natural Systems. Island Press, Washington DC.

GWP-TAC (Global Water Partnership - Technical Advisory Committee) (2000). Integrated Water Resources Management. TAC Background Papers No. 4, GWP, Stockholm, Sweden.

Haney, A. and Power, R.L. (1996). Adaptive management for sound ecosystem management. Env. Man., 20(6), 879-886.

Hatcher, K. (1981). A system's view of integrated water resources management. In Symposium Proceedings: Unified River Basin Management: Stage 2, Allee, D., et al. (eds), American Water Resources Association, Minneapolis, Minnesota, pp. 145-160.

Holling, C.S. (ed.) (1978). Adaptive Environmental Assessment and Management. Wiley, Chichester, UK.

ICWE (1992). The Dublin statement and report of the conference. International Conference on Water and the Environment: Development Issues for the 21st century, 26-31 January, Dublin, Ireland.

IWA UNEP (2002). Industry as a partner for sustainable development: Water Management, IWA/UNEP, London, UK.

Jewitt, G. (2002). Can Integrated Water Resources Management sustain the provision of ecosystem goods and services? Phys. Chem. Earth., 27, 887-895.

Jonker, L. (2002). Integrated water resources management: theory, practice, cases. Phys. Chem. Earth., 27, $719-720$.

Kabat, P., Schulze, R.E., Hellmuth, M.E. and Veraart, J.A. (eds) (2002). Coping with impacts of climate variability and climate change in water management: a scoping paper, DWC-Report no. DWCSSO-01 (2002). International Secretariat of the Dialogue on Water and Climate, Wageningen, The Netherlands.

Margerum, R.D. and Born, S.M. (1995). Integrated environmental management: moving from theory to practice. J. Env. Plann. Man., 38(3), 371-391.

Mitchell, B. (1990). Patterns and Implications. In Integrated Water Management: International Experiences and Perspectives, Mitchell, B. (ed), Belhaven Press, London, UK, pp. 203-218.

Radif, A.A. (1999). Integrated water resources management (IWRM): an approach to face the challenges of the next century and to avert future crises. Desal, 124, 145-153.

Reisner, M. (1986). Cadillac Desert: The American West and its Disappearing Water. Viking, New York.

Schulze, R.E. (2001). Modelling as a tool in integrated water resources management. Conceptual issues and case study applications, School of Bioresources Engineering and Environmental Hydrology, University of Natal, Pietermaritzburg, South Africa. 
Turton, A.R. (1999). Water scarcity and social adaptive capacity: Towards an understanding of the social dynamics of water demand management in developing countries. MEWREW Occasional paper No. 9 (Water Issues Study Group, SOAS).

United Nations (1993). Agenda 21: Programme of Action for Sustainable Development. United Nations, New York.

Walters, C. (1986). Adaptive Management of Renewable Resources. McGraw Hill, New York.

Walther, P. (1987). Against idealistic beliefs in the problem-solving capacities of integrated resource management. Env. Man., 11(4), 439-446.

Westcoat, J.L. (1992). Book review of Mitchell, B. (1990). Global Env. Ch. March 1992. pp. 70-71.

White, G.F. (1998). Reflections on the 50-year international search for integrated water management. Wat. Pol., 1, 21-27. 